\title{
PREPRINT OF OMAE2019-95979
}

\author{
Presented at the 38th International Conference on Ocean, Offshore \& Arctic Engineering, OMAE2019, June 9-14, \\ 2019, Glasgow, Scotland, UK
}

\section{DESIGN METHODOLOGY FOR A FLOATING OFFSHORE WIND TURBINE LARGE- SCALE OUTDOOR PROTOTYPE}

\author{
Alessandro Fontanella* \\ Politecnico di Milano \\ Milano, Italy \\ Sara Muggiasca \\ Politecnico di Milano \\ Milano, Italy
}

\author{
Federico Taruffi \\ Politecnico di Milano \\ Milano, Italy \\ Marco Belloli \\ Politecnico di Milano \\ Milano, Italy
}

\begin{abstract}
This paper discusses the methodology introduced by the authors to design a large-scale wind turbine model starting from the DTU 10MW RWT. The wind turbine will be coupled with the model of a multi-purpose floating structure, designed within the EU H2020 Blue Growth Farm project, and it will be deployed at the Natural Ocean Engineering Laboratory (NOEL). In this paper the different strategies used to design the wind turbine model rotor, tower and nacelle are discussed, focusing on how it has been possible to reproduce the full-scale system aero-elastic response while ensuring the same functionalities of a real wind turbine.
\end{abstract}

\section{INTRODUCTION}

The EU H2020 Blue Growth Farm project aims at developing an efficient, cost-competitive, environmentallyfriendly and multi-purpose offshore farm exploiting a modular floating structure. Wave energy converters and a single wind turbine, based on the DTU 10MW reference wind turbine (RWT), are integrated with aquaculture for profitable applications in different open sea scenarios. The development of the multi-purpose floating structure is going to be supported by experimental data collected on a large-scale mode (outdoorscaled prototype) to be deployed at the Natural Ocean Engineering Laboratory (NOEL) in Reggio Calabria (Italy). The aero/hydro characteristics of the outdoor prototype must be obtained by appropriate scaling so that experimental data will be significative for the design of the full-scale system. In particular, hydrodynamic loads on the platform hull, mooring lines dynamics, structural loads and wind turbine rotor forces (included those generated by the machine control system) must be simultaneously reproduced in the environmental conditions found at NOEL site. The paper presents the scaling procedure adopted by the authors to properly design the wind turbine outdoor-prototype within the objectives defined by the Blue
Growth Farm project (for the multi-purpose floating structure model project refer to Li et al 2019, Ruzzo et al 2109).

\section{NOMENCLATURE}

$$
\begin{aligned}
& \text { RWT } \\
& \text { FOWT } \\
& \mathrm{U}[\mathrm{m} / \mathrm{s}] \\
& \mathrm{g}\left[\mathrm{m} / \mathrm{s}^{2}\right] \\
& \mathrm{L}[\mathrm{m}] \\
& \mathrm{Hs} \\
& \mathrm{U}_{10 \mathrm{~min}}[\mathrm{~m} / \mathrm{s}] \\
& \lambda[-] \\
& F r=\frac{U}{\sqrt{g L}} \\
& \operatorname{Re}=\frac{U L}{v} \\
& \nu\left[\mathrm{m}^{2} / \mathrm{s}\right] \\
& \mathrm{t}[\mathrm{m}] \\
& \mathrm{c}[\mathrm{m}] \\
& \mathrm{CL}_{\mathrm{L}}[-] \\
& \text { AoA }[\mathrm{deg}] \\
& \mathrm{E}\left[\mathrm{N} / \mathrm{m}^{2}\right] \\
& \mathrm{EJ}\left[\mathrm{N} \mathrm{\textrm {m } ^ { 2 }}\right]
\end{aligned}
$$

\section{DTU 10MW REFERENCE WIND TURBINE}

The DTU $10 \mathrm{MW}$ wind turbine, which is the full-scale reference machine for this work, was firstly designed in the framework of the Light Rotor project in 2012 (Bak et al. 2012), as a rational upscale of the NREL 5 MW (Jonkman et al 2009). Later on, the Light Rotor project design evolved in the nowadays publicly available reference design, released by DTU (Bak et al 
2013). Recently, the DTU 10 MW RWT has been used in numerous research activities related to wind energy development, ranging from wind farm optimization to offshore wind turbine simulation or also for numerical tools benchmark and validation (Bayati et al 2018a, Bayati et al 2018b). Table 1 reports the main DTU $10 \mathrm{MW}$ specifications in terms of geometry, masses and operating wind speeds.

Table 1. DTU 10 MW turbine specifications.

\begin{tabular}{lcr}
\hline Parameter & Value & Units \\
\hline Cut in wind speed & 4 & $\mathrm{~m} / \mathrm{s}$ \\
Cut out wind speed & 25 & $\mathrm{~m} / \mathrm{s}$ \\
Rated wind speed & 11.4 & $\mathrm{~m} / \mathrm{s}$ \\
Rotor Diameter & 178.3 & $\mathrm{~m}$ \\
Hub Diameter & 5.6 & $\mathrm{~m}$ \\
Hub Height & 119 & $\mathrm{~m}$ \\
Minimum Rotor Speed & 6 & $\mathrm{rpm}$ \\
Maximum Rotor Speed & 9.6 & $\mathrm{rpm}$ \\
Blade Prebend & 3.332 & $\mathrm{~m}$ \\
Rotor Mass & 228 & $\mathrm{t}$ \\
Nacelle Mass & 446 & $\mathrm{t}$ \\
Tower Mass & 628.4 & $\mathrm{t}$ \\
\hline
\end{tabular}

\section{SCALING PROCEDURE}

The wind turbine outdoor scaled protype represents a challenging project that has to satisfy, at the same time, the requirements of a classic aeroelastic scale model and of a real small-scale wind turbine. The real challenge is represented by the necessity to scale a machine and not only a passive structure. This requires using a performance scaling approach in order to obtain a mechanical system able to grant the same functionalities as the full-scale reference. The typical design strategies adopted to realize aeroelastic scale models must be revised in order to include also criteria that are generally used in the design of real structures. In particular, the interaction with the real-life environment, the safety issues in the area of the laboratory and the characteristics of the local wind must be considered in doing structural design of the wind-turbine outdoor-scaled prototype. A further complication is added by the special environmental conditions met at the test site. Experiments will be performed in a so-called natural laboratory where met-ocean conditions can be considered a scaled representation of those expected at typical FOWT deployment sites. Here, differently from traditional wind tunnel and ocean basin testing, it is not possible to control wind and wave characteristics, thus the design of the experiment has to rely on probabilistic data only. Moreover, the interdependence of wind and waves found at the NOEL site is not a perfectly scaled version of what is found at target FOWT deployment sites. This imposes to find a compromise in the definition of the scaling parameters to simultaneously match hydrodynamic and aerodynamic-related phenomena.

Froude scaling, commonly used in ocean basing testing, is mandatory since the hydrodynamic interaction of the floater is driven by gravity. The Froude similarity is obtained imposing the equality of the Froude Number between model scale and fullscale, where Froude number is defined as:

$F r=\frac{U}{\sqrt{g L}}$

According to the project requirements, the scaled floating structure must be based on a quite large length scale, within the range 1:10-1:20. In order to choose a proper value it is important to evaluate the met-ocean conditions at NOEL with respect to a possible full-scale deployment site. The Golfe de Fos was chosen as reference site: this is an area at about $30-40 \mathrm{~km}$ offshore of Fos sur Mer, in the Département des Bouches du Rhône, in the region of Provence-Alpes-Côte d'Azur, Southern France. The same site was already selected by the EU H2020 LIFE50+ project. A complete database of its met-ocean data is available for calculation in Gómez et al 2015 and Krieger et al 2105 (see Table 2 for the main data).

Table 2. Met-ocean condition of Golfe de Fos.

\begin{tabular}{lcc}
\hline Depth & $\mathrm{m}$ & $50-100$ \\
Mean annual wind speed at 100m ASL & $\mathrm{m} / \mathrm{s}$ & $>10$ \\
Mean peak wind gust & $\mathrm{m} / \mathrm{s}$ & Gust factor 1.4 \\
Type of soil & - & Sand/Mud \\
Mean annual significant wave height & $\mathrm{m}$ & 0.8 \\
Peak period & $\mathrm{s}$ & 4.5 \\
1 year significant wave height & $\mathrm{m}$ & 3.4 \\
1 year peak period & $\mathrm{s}$ & 8.5 \\
50 years significant wave height & $\mathrm{m}$ & 7 \\
50 years peak period & $\mathrm{s}$ & 9.5 \\
\hline
\end{tabular}

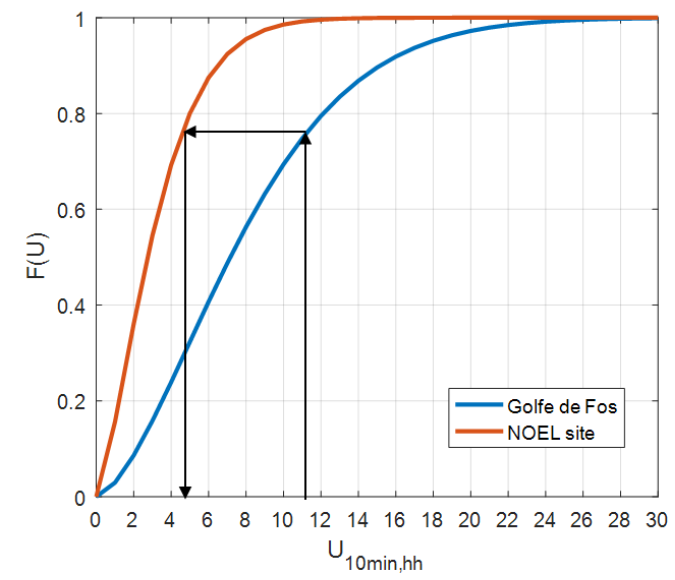

Figure 1. Cumulative distribution functions of the wind velocities for Golfe de Fos and NOEL site - The arrows identify the rated wind velocity for both sites.

In Figure 1 are reported the cumulative distribution functions of the wind velocities relative to Golfe de Fos, obtained from publicly available data, and to NOEL site, extracted from a long-term database provided by the NOEL laboratory. It is 
possible to note that, keeping constant the probability of exceedance, the full-scale wind turbine rated hub-height $(\mathrm{HH})$ wind speed of $11.4 \mathrm{~m} / \mathrm{s}$ corresponds to $4.76 \mathrm{~m} / \mathrm{s}$ at NOEL at a generic hub-height of $10 \mathrm{~m}$, that is assumed reasonable for a length scale between 1:10 and 1:20. This correspondence can be used to define the wind speed scale factor for the experiment. This would ensure the same probability to have the wind turbine working in partial or full-load conditions for both model and fullscale.

Comparing the significative wave height conditions in the two sites (see Figure 2), it is possible to define the ratio between the expected value of $\mathrm{Hs}$ at the rated wind speed for the model and the prototype. The results of this analysis are reported in

Table 3. The discrepancy between the wave/wind direct comparison and Froude similarity was judged acceptable, considering that it is not possible to control the natural excitation met at the laboratory, and that the order of magnitude of the scaled quantities is respected.

Starting from this analysis it was decided to fix $5 \mathrm{~m} / \mathrm{s}$ as the rated speed for the model wind turbine: the equivalence of the probability of exceedance seemed to be a good criterion to grant the occurrence of the operating conditions for the wind turbine during the experimental campaign. The identified wind speed $(5$ $\mathbf{m} / \mathbf{s}$ ) was also judged a proper dimensioning value, since the wind turbine design resulting from the related loads was sound also from a structural point of view. The so-defined velocity scale would be used for aerodynamic design. As far as it concerns the length scale factor, this was fixed to $1: 15$, slightly increasing the value of

Table 3. This value is large enough to give an acceptable improvement with respect to other tests planned in the wave tank of the Ecole Centrale de Nantes (1:40-1-50) and still representative for the wind/wave correlation at NOEL. On the other hand, it was considered preferable to limit the dimensions of the whole outdoor prototype in order to respect economic constrains, to facilitate its installation at NOEL and to promote the community acceptance of a quite large wind turbine in the close-shore location of the laboratory. This decision was shared among the other EU project partners involved in the design of the whole outdoor prototype structure.

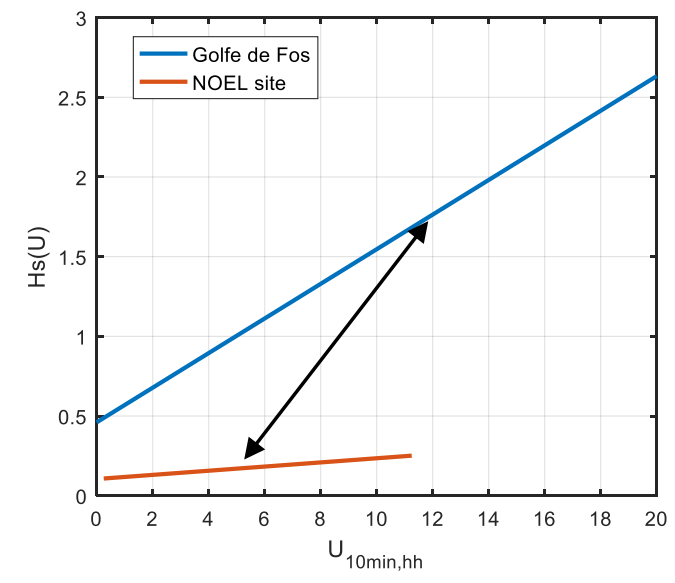

Figure 2. Significative wave height as a function of the wind velocity for Golfe de Fos and NOEL site - The arrows identify the rated wind velocity for both sites.

Table 3. Wind/wave scaling parameters.

\begin{tabular}{lclc}
\hline Length ratio & 10.3 & $\begin{array}{l}\text { Corresponding Froude } \\
\text { Velocity parameter }\end{array}$ & 3.2 \\
$H_{S}^{R} / H_{S}^{M}$ & & $\begin{array}{l}\text { Corresponding Froude } \\
\text { Velocity ratio }\end{array}$ & 5.7 \\
$U_{10 \mathrm{~min}}^{R} / U_{10 \mathrm{~min}}^{M}$ & 2.4 & \begin{tabular}{l} 
Length parameter \\
\hline
\end{tabular} & \\
\hline
\end{tabular}

Once the length scale factor was defined, Froude similarity was used to define the scaling parameter for masses, forces and time (i.e. frequency) as summarized in Table 4. These parameters allowed to scale the tower, matching its first fore-aft (FA) sideside (SS) modes (frequencies and shapes), the global mass and the main geometry. More details are included in the next section 'Tower scaling process'.

Table 4. Scaling parameters.

\begin{tabular}{llr}
\hline Length scale & $\lambda_{L}$ & 15 \\
Velocity scale (no Froude) & $\lambda_{V}$ & 2.4 \\
Mass scale & $\lambda_{M}=\lambda_{L}^{3}$ & 3375 \\
Moment of inertia scale & $\lambda_{J}=\lambda_{L}^{4}$ & 50625 \\
Force scale & $\lambda_{F}=\lambda_{L}^{3}$ & 3375 \\
Time scale & $\lambda_{T}=\sqrt{\lambda_{L}}$ & 3.9 \\
\hline
\end{tabular}

The outdoor scaled prototype rotor has to operate at $\mathrm{Re}$ numbers different from those of the RWT, thus a specific strategy must be used, in the design of the model rotor, in order to correctly scale the aerodynamic loads. By geometrically scaling the wind turbine blades, a substantially lower power and thrust force, not in line with the full-scale, is experienced (Robertson et al 2013). It was then necessary to adopt a modified scaling approach, called "performance scaling" (De Ridder et al 2014, 
Bayati et al 2017a Bayati et al 2017b). The main aim of this approach is to obtain the scaled thrust force, at the wind speed scaled according to the parameters reported in Table 4. This is generally achieved by redesigning the blades geometry in order to provide, under scaled wind, a thrust force and power coefficient as close as possible to the full-scale wind turbine. New airfoils with the required efficiency at the Reynolds Number range of the scaled prototype had to be selected. The complete blade geometry was defined in terms of chord length, thickness and twist angle as function of the blade station (i.e. radial distance from rotor apex), fixing the thrust force as main target of the optimization procedure. The desired performance will be finally reached controlling the rotor with a variable-speed variable-pitch (VS-VP) controller. A more detailed description of the rotor design is provided in the next section 'Rotor scaling process'.

Finally, the nacelle sizing procedure, in terms of global mass and overall indicative dimensions, was based on Froude similarity. Although, it is important to consider that the components inside the nacelle must ensure the typical functionalities of a real wind turbine, in particular the control of rotor collective pitch angle and generator torque. Further details will be provided in the 'Nacelle scaling process' section.

\section{ROTOR SCALING PROCESS}

The performance scaling procedure was applied to properly scale the rotor, following the steps described in Bayati et al 2017a. As anticipated in the previous chapter, this procedure imposes to re-design blades geometry starting from a different airfoil profile. In particular, for the present project this was chosen from Lion et al 1998, where a wide database of airfoil shapes optimized for low Reynolds numbers is provided. In Figure 3 the shape of one of the DTU 10 MW airfoils (FFA-W3241) and the SG6040, that was selected as the unique profile for the outdoor scaled prototype blade, are compared. The SG6040 profile was judged a good compromise between sensitivity to flow separation and offered structural stiffness. The thickness over chord length (16\%) is lower than the one of the RWT profiles (24\%), but large enough to grant good structural performances for the chosen length scale.

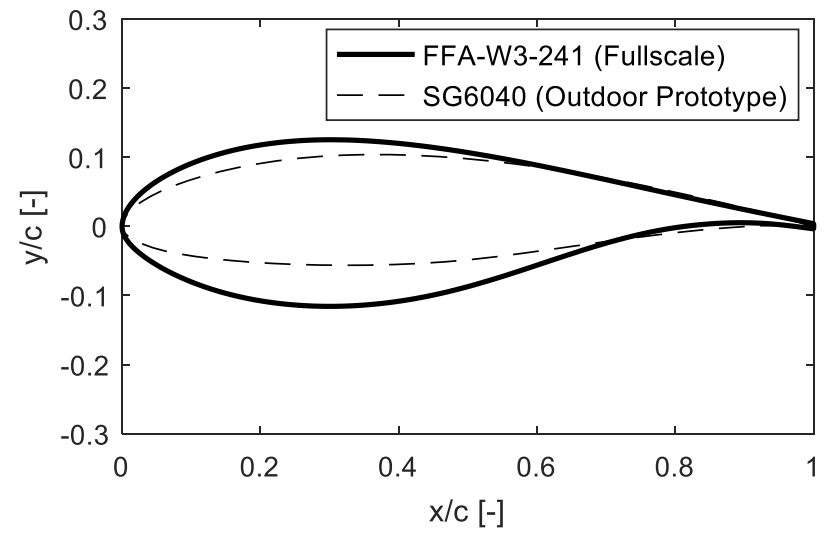

Figure 3. Model airfoil (SG6040, dashed line) and reference airfoil (FFA-W3-240, solid line).

Moreover, as shown in the available literature data, the SG6040 lift coefficient is linear with respect to the angle of attack in a wide region and this is a suitable behavior for wind turbine blades that generally work far from stall conditions, (see the lift coefficient of the chosen profile compared to the reference coefficient trend in Figure 4). It is planned to experimentally verify the lift coefficient data through $2 \mathrm{D}$ wind tunnel tests on the selected profile, at the Reynolds Numbers expected for the wind turbine prototype in the operating conditions to be faced during tests. It is important to point out that, in opposition to the procedure described in Bayati et al $2017 \mathrm{a}$, the rotor aerodynamics was firstly defined without considering the structural behavior. Moreover, an additional constrain was imposed in the maximum length of the blades, limiting the rotor diameter to $10 \mathrm{~m}$. This constrain was imposed to limit the maximum dimension of the wind turbine prototype rotor and to simplify its structural design: rotor dimension reduction allows to reduce costs, to facilitate the design and the installation and to promote the community acceptance of a quite large structure in the close-shore location of the NOEL laboratory.

Once the airfoil profile was defined, the blade geometry was optimized in order to match the scaled lift force along the blade span, finally matching the DTU $10 \mathrm{MW}$ scaled thrust force. A consolidated procedure (Bayati et al 2017a) that permits to define the geometry of the blade and the dimension of the rotor was used to obtain chord, twist and blade thickness as a function of the blade station. Results of the above mentioned designed procedure are reported in Figure 5. 


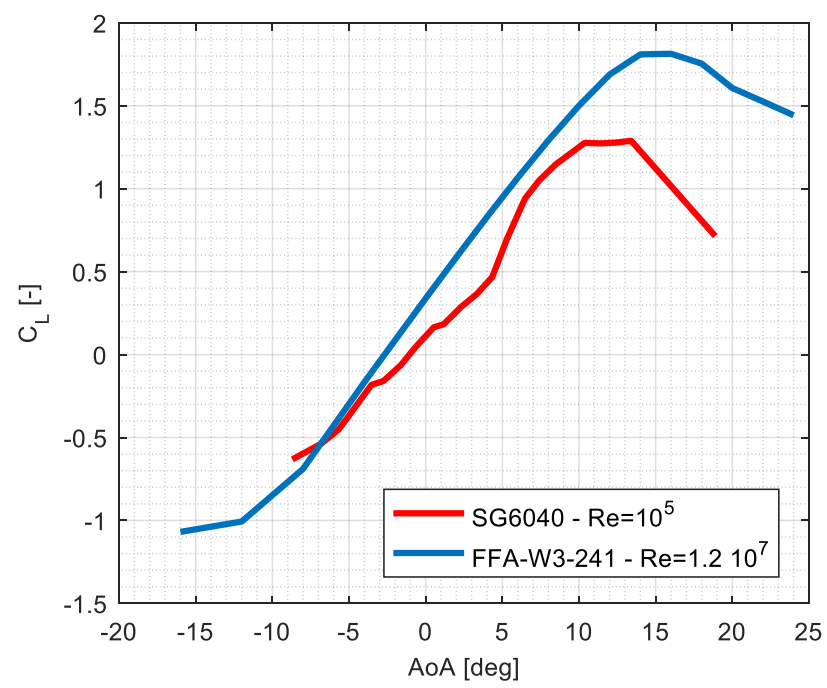

Figure 4. Reference and model airfoil lift coefficient comparison.
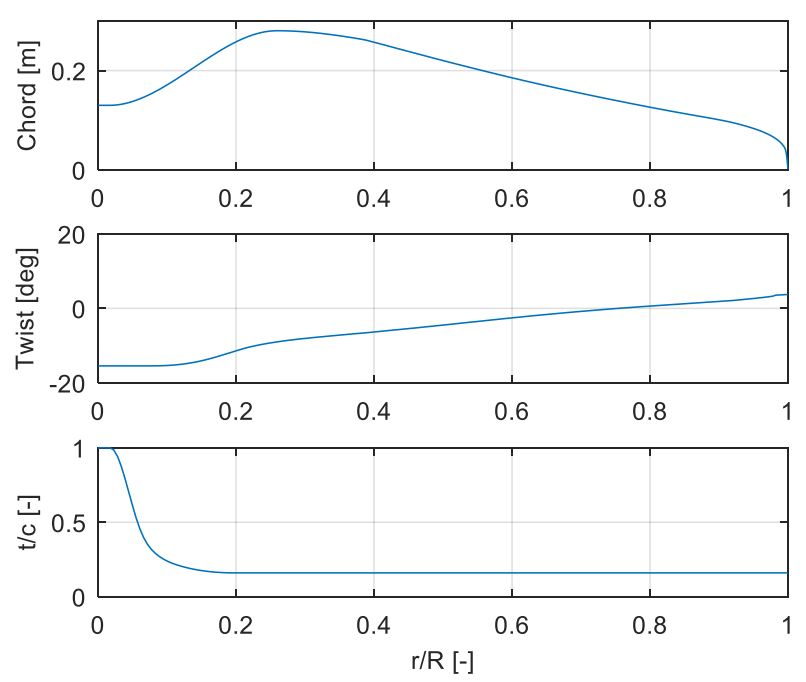

Figure 5. Chord, twist and $t / c$ value vs non-dimensional blade radial position.

The optimal design, from an aerodynamic point of view, for the prototype rotor was obtained with a diameter of about $6.8 \mathrm{~m}$. The so-obtained rotor design was verified though FAST v8.16 steady-state simulations. The blade aerodynamic were implemented in AeroDyn 14 that is one of the most used, freelyavailable, rotor aerodynamic solvers. The numerical simulation results in terms of thrust force are reported in Figure 6 where are also compared to the target curve of the DTU 10MW RWT. The reference thrust was obtained by scaling the force according to Froude (see scale factors reported in Table 4) and shifting the curve in order to match the model rated wind speed. It is possible to observe the good agreement between the two curves.

The blades structural design is, at present, in progress, having as main targets the first flap-wise frequency, and the rotor global mass and moment of inertia. The blade must also be verified with respect to the maximum load conditions expected at the installation site. In order to realize the structural design, composite materials will be considered and an internal geometry similar to a real blade (with shear webs/spar caps) will be arranged.

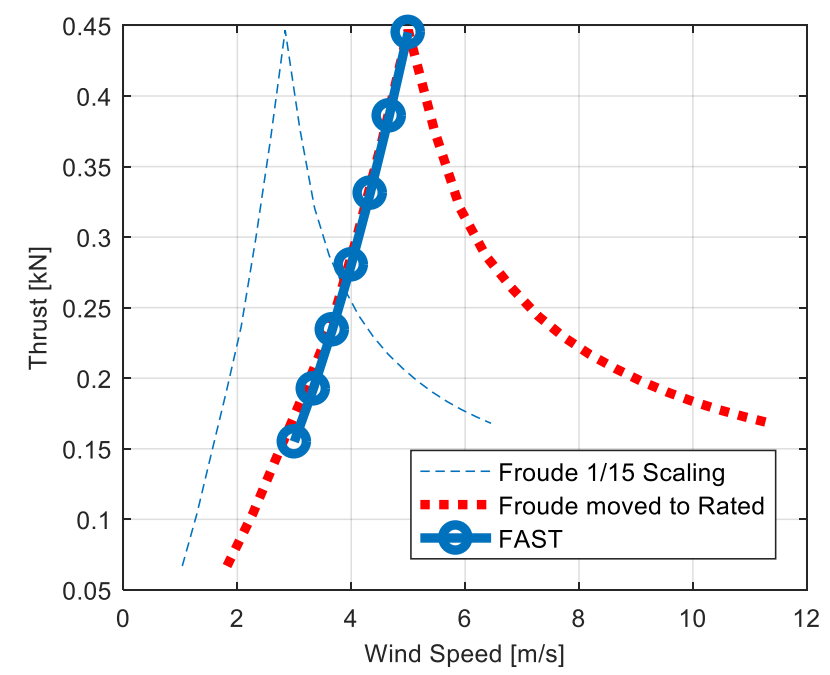

Figure 6. Comparison of the thrust force computed using FAST and the refence scaled curve.

\section{TOWER SCALING PROCESS}

The wind turbine tower must be scaled in agreement to Froude law, having as main target parameters the stiffness, mass, shapes and frequencies of the first two bending modes (fore-aft and side-side). The external geometry should be scaled considering the defined length scale factor and introducing some simplifications in the tower shape. In particular the external diameter is kept constant while the real tower is tapered.

The aeroelastic models commonly realized for laboratory tests are built in agreement with ASCE guidelines, as an equivalent spine model (ASCE, 1998) whose structural properties are chosen to tune the first frequencies and modal shapes. The model is then provided by a non-structural outer skin to reproduce the external geometry. In this case, as the model will be installed in an outdoor environment, subjected to natural excitation, a different strategy was considered. Since the most important constrain is represented by the bending modes frequencies, the tower bending stiffness EJ and linear mass must be properly scaled according to the parameters of Table 5 . The prototype tower was designed as an aluminum tube dimensioned in order to match the scaled EJ. The tube characteristics compared to the scaled DTU 10MW tower characteristics are summarized in Table 6. It is possible to notice that real tower diameter and bending stiffness change along the height whereas these are constant for the prototype. Moreover, being the aluminum tube lighter than required, the target mass value will be obtained adding local masses, distributed along the height. 
Finally, in order to match EJ and then the frequencies, it was necessary to define an external diameter smaller than target.

Table 5. Scaling parameters for the wind turbine tower.

\begin{tabular}{llr}
\hline Length scale & $\lambda_{L}$ & 15 \\
Velocity scale & $\lambda_{V}=\sqrt{\lambda_{L}}$ & 3.9 \\
Mass scale & $\lambda_{M}=\lambda_{L}^{3}$ & 3375 \\
Force scale & $\lambda_{F}=\lambda_{L}^{2} \lambda_{V}^{2}$ & 3375 \\
Time scale & $\lambda_{T}=\lambda_{L} / \lambda_{V}$ & 3.9 \\
Stiffness scale (EJ) & $\lambda_{E J}=\lambda_{L}^{5}$ & 759375 \\
\hline
\end{tabular}

Table 6. Tower characteristics.

\begin{tabular}{|c|c|c|}
\hline & $\begin{array}{l}\text { Scaled DTU } \\
10 \mathrm{MW}\end{array}$ & $\begin{array}{l}\text { Outdoor } \\
\text { prototype }\end{array}$ \\
\hline Tower Mass [kg] & 186 & $72^{*}$ \\
\hline $\mathrm{E}\left[\mathrm{N} / \mathrm{m}^{2}\right]$ & $2.10 \mathrm{E}+11$ & $7.50 \mathrm{E}+10$ \\
\hline Material & steel & aluminium \\
\hline $\mathrm{EJ}\left[\mathrm{N} \mathrm{m}{ }^{2}\right]$ & $3.5 \mathrm{e} 5-2.3 \mathrm{e} 6$ & $2.30 \mathrm{E}+06$ \\
\hline Frequency $[\mathrm{Hz}]$ & 1.09 & 0.97 \\
\hline External diameter $[\mathrm{m}]$ & $0.37-0.55$ & 0.28 \\
\hline
\end{tabular}

${ }^{*}$ aluminium tube mass, without considering added masses

On the other hand, it must be underlined that, even by properly scaling the tower geometry, there would be a strong discrepancy in terms of Reynolds Number between prototype and full-scale. In particular the real tower is in the supercritical Reynolds Number range whereas the model falls in the critical one. In order to simulate the required high-Reynolds Number behaviour, the model tower surface roughness will be artificially increased. This is going to lead to a greater equivalent Reynolds Number but also to an increased drag coefficient with respect to a smooth cylinder. The lower diameter resulting from structural design would then be acceptable also in consideration to the higher drag coefficient expected due to the surface roughness.

A FEM model of the tower prototype was realized in order to check the flexural frequencies which values are reported in Table 6 . As visible, these are very close to target. The prototype behaviour was also checked in terms of modal shape and compared to the deflected shape of the DTU $10 \mathrm{MW}$ : the comparison is reported in Figure 7 where a good agreement is observed.

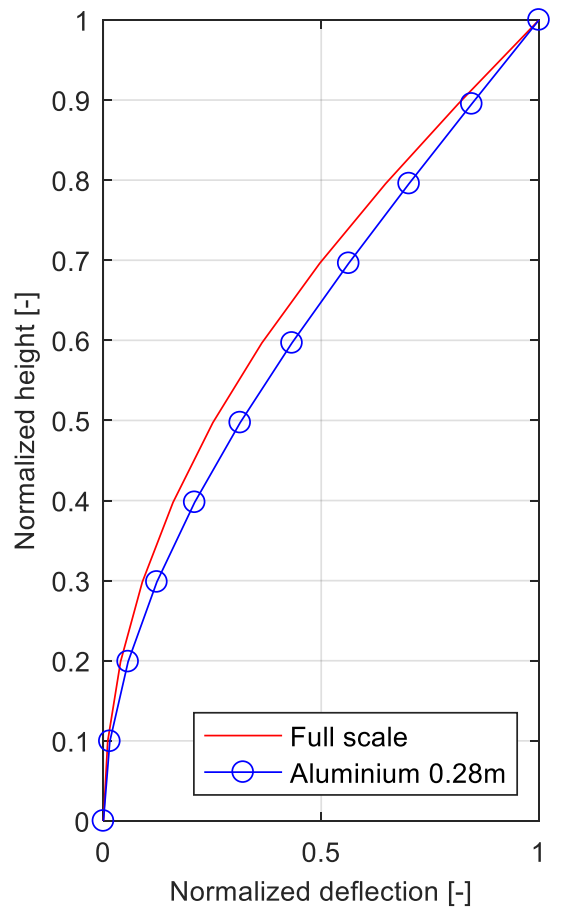

Figure 7. Comparison between full-scale and prototype of the FEM results in terms of modal shape.

\section{NACELLE SCALING PROCESS}

As previously stated, the nacelle scaling procedure starts from Froude parameters, in order to define the overall dimensions and the global mass. Although these constrains are important, the internal components of the nacelle must be also properly designed, as for a real wind turbine, to satisfy the required control functionalities. Particular care was devoted in the mechanical connections and drive systems design. As far it concerns connections, the most important are:

- connection between the tower and the nacelle: in order to simplify the model assembly, it was required to have a joint that permits an easy nacelle dismounting;

- connection between the rotor and the nacelle: this joint was required to handle a cantilever load;

- connection between the blades and the rotor: also in this case cantilever loads must be supported.

The main drive systems are:

- nacelle yaw: this motion is actuated with a couple of gears, one integrated in the apical tower section and the other connected to a motor positioned inside the nacelle assembly (in order to guarantee an easy disassembly process). A brake is also needed to control the rotation;

- rotor collective blade pitch: the rotor pitch angle can be actuated either using a collective system or an individual one. The latter is preferable since it would allow to achieve good control performances at low cost with a high level of precision in the motion control; 
- clutch-brake system: this system could be eventually used for both braking the nacelle yaw and the wind turbine drivetrain. It would allow to disconnect the driven part from the user and then to obtain a better control over the part that has to be stopped. The main design concern is about the amount of energy that has to be dissipated during deceleration;

- gearmotor and generator brake system: these systems have to be defined together as a function of the chosen torque actuator (i.e. wind turbine generator).

\section{CONCLUSIONS}

This paper presents the scaling procedure introduced by the authors to design a large-scale aeroelastic model of a floating wind turbine. Different strategies must be used to properly design rotor, tower and nacelle, in order to obtain an aeroelastic structure, with performances comparable with a full-scale reference wind turbine. Moreover, as the model will be installed in an outdoor natural laboratory, also criteria that are generally used in the design of real structures must be considered in the scaling process.

\section{ACKNOWLEDGMENTS}

This work has been produced in the framework of the Blue Growth Farm project (http://www.thebluegrowthfarm.eu/), which has received funding from the European Union's Horizon 2020 research and innovation programme under Grant Agreement number 774426. The content of the work does not report the opinion of the European Commission and reflects only the views of the author(s), including errors or omissions. The European Commission is also not liable for any use that may be made of the information contained herein.

\section{REFERENCES}

Li, L., Collu, M., Abhinav, A. K., Ruzzo, C., Arena, F., 2019. Analysis of the Coupled Dynamics of an Offshore Floating Multi-Purpose Platform, Part A: Rigid-Body Analysis, submitted to International Conference on Offshore Mechanics and Arctic Engineering - OMAE2019, Glasgow, UK.

Ruzzo C., Failla G., Arena F., Collu M., Li L., Mariotti A., 2019. Analysis of the coupled dynamics of an offshore multipurpose platform, part B: hydro-elastic analysis with flexible support platform, submitted to International Conference on Offshore Mechanics and Arctic Engineering - OMAE2019, Glasgow, UK.

Bak C., Bitsche, R., Yde, A., Kim, T., Hansen, M. H., Zahle, F., Behrens, T., 2012, Light Rotor: the 10-MW reference wind turbine, Proceedings of EWEA 2012-European Wind Energy Conference. European Wind Energy Association (EWEA).

Jonkman, J., Butterfield, S., Musial, W., Scott, G., 2009. Definition of a 5-MW Reference Wind Turbine for Offshore System Development Technical Report NREL/TP-500-38060. NREL National Renewable Energy Laboratory.

Bak, C. et al, 2013. The DTU 10-MW Reference Wind Turbine. Technical University of Denmark, DTU Wind Energy, Denmark.
Bayati, I., Belloli, M., Bernini, L., Boorsma, K., Caboni, M., Cormier, M., Mikkelsen, R., Serdeczny, M., Lutz, T., and Zasso, A., 2018. "UNAFLOW project: UNsteady Aerodynamics of FLOating Wind tur- bines". Journal of Physics: Conference Series, 1037(7). http://stacks.iop.org/17426596/1037/i=7/a=072037.

Bayati, I., Bernini, L., Zanotti, A., Belloli, M., and Zasso, A., 2018. "Experimental investigation of the un- steady aerodynamics of FOWT through PIV and hot- wire wake measurements". Journal of Physics: Conference Series, 1037(5). http://stacks.iop.org/1742- 6596/1037/i=5/a=052024.

Gómez, P., Sánchez, G., Llana, A. and Gonzalez, G., 2015. "Deliverable D1.1 Oceanographic and meteorological conditions for the design".

Krieger, A., Ramachandran, G. K. V., Vita, L., Almería, G. G., Berque, J. and Aguirre, G., 2015. "Deliverable D7.2 Design Basis".

Robertson, A. N., Jonkman, J. M., Goupee, A. J., Coulling, A. J., Prowell, I., Browning, J., Masciola, M. D., Molta, P., 2013. Summary of conclusions and recommendations drawn from the DeepCwind scaled floating offshore wind system test campaign, Proc. 32nd ASME International Conference on Offshore Mechanics and Arctic Engineering, Nantes, France.

De Ridder, E.J., Otto, W., Zondervan, G.J., Huijs, F. and Vaz, G., 2014. Development of a scaled down floating wind turbine for offshore basin testing, Proc. 33rd ASME International Conference on Ocean, Offshore and Arctic Engineering.

Bayati I., Belloli M., Bernini L. Zasso A., 2017. Aerodynamic design methodology for wind tunnel tests of wind turbine rotors. Journal of Wind Engineering and Industrial Aerodynamics. 167. 217-227. 10.1016/j.jweia.2017.05.004.

Bayati, I., Belloli, M., Bernini, L., Giberti, H., Zasso, A. Scale model technology for floating offshore wind turbines (2017) IET Renewable Power Generation, 11 (9), pp. 1120-11

Lyon, C. A., Broeren, A. P., Gigure, P., Gopalarathnam, A., Selig, M.S., 1998. Summary of Low-speed Airfoil Data vol. 3. SoarTech Publications, Virginia Beach, VA.

ASCE, 1998. Wind tunnel studies of buildings and structures. American Society of Civil Engineers, Reston, VA, iD:3985612. 
Preprint of OMAE2019-95979 